\title{
Evaluation of the quality of three canal obturation techniques: A laboratory study
}

\author{
Khaly Bane ${ }^{1, *}$, Seydina O. Niang ${ }^{2}$, Fatou Léye-Benoist ${ }^{3}$, Kouadio Florent Kouakou ${ }^{4}$, Babacar Touré ${ }^{5}$ \\ ${ }^{1,3}$ Associate Professor, ${ }^{2,4}$ Lecturer, ${ }^{5}$ Professor, Dept. of Odontology, Cheikh Anta Diop University of Dakar, Senegal, ${ }^{4}$ Félix \\ Houphouet Boigny University, Abidjan, Côte d'Ivoire
}

*Corresponding Author:

E-mail: khalyb74@yahoo.fr

\begin{abstract}
Introduction: The aim of the present study was to compare the filling capacity of cold lateral condensation, warm vertical condensation and Thermafil ${ }^{\circledR}$ in severely curved canals of extracted human molars.

Material and Methods: Mesiobuccal (MB) canals of 90 mandibular molars with angles of curvature ranging between $25^{\circ}$ and $35^{\circ}$ and radius of 5 to $9 \mathrm{~mm}$ curvature were divided into three groups $(n=30$ each). In each group, canals were instrumented with ProTaper $^{\circledR}$ and obturated either by cold lateral condensation (L), warm vertical condensation (V) or Thermafil ${ }^{\circledR}(\mathrm{T})$. The limit was considered adequate (0-2 mm to the radiologic apex), or with over-obturation or with over-extension. The presence of voids and their location in the canal was also explored and the density was evaluated. Data were analyzed using the Kruskal Wallis test. Differences were significant with a two-sided $\alpha<0.05$.

Results: The majority of obturations with adequate limit was from group V (66.8\%). Group T displayed the highest proportion of over obturation (46.7\%) and group L the highest proportion of over-extension $(33.3 \%)(\mathrm{P}<0.05)$. Concerning the density, group $\mathrm{T}$ presented the best results in terms of the absence of voids $(16.7 \%)(\mathrm{P}<0.05)$.

Conclusion: Warm vertical condensation and Thermafil ${ }^{\circledR}$ techniques give the best results for the obturation of curved canals in respect to limit and density.
\end{abstract}

Keywords: Apical limit, Cold lateral condensation, Obturation, Thermafil ${ }^{\circledR}$, Voids, Warm vertical condensation.

\section{Introduction}

Endodontic system obturation is the essential complement of root canal preparation. ${ }^{1}$ It must be tridimensional, waterproof and durable in order to maintain the achievements of the steps of debridement and formatting. ${ }^{2,3}$ There are many techniques to that end with their advantages and disadvantages.

Cold lateral condensation is a classical technique still being used due to the malleability of the gutta-percha which is spread and adapted in three dimensions over the already prepared canal walls. It is easy to perform at a relatively low cost. ${ }^{4-6}$ It has been the technique of choice for a long period of time but its major disadvantage is related to the excess of sealer.

Warm vertical condensation was then proposed as an alternative to improve the results of canal sealing. It uses the thermoplastic properties of the gutta-percha to adapt it to the canal morphology under controlled pressure. Its sealing capability is excellent at a relatively low cost. ${ }^{7}$

The introduction of endodontic continuous motion for root canal shaping led to the creation of new obturation techniques adapted to the resulting shapes. ${ }^{8}$ Thermafil $^{\circledR}$ (Dentsply Maillefer, Ballaigues, Switzerland) is one of those modern techniques in which case the obturator is made of a flexible plastic tutor (with standard dimensions) covered by gutta-percha. It contains a gutter that facilitates the partial (canal anchoring) or total (retreatment) desobturation. It also displays the sink marks. The obturator is heated in an ovenprior to its introduction and condensation inside the canal system. The technique is easy to perform and ensures excellent sealing. ${ }^{9,10}$
The aim of the present study was to compare the filling capacity of cold lateral condensation, warm verticalcondensation and Thermafil $^{\circledR}$ techniques in severely curved mesiobuccal (MB) canals of extracted human mandibular molars. The null hypothesis was that there is no difference between these techniques with respect to densityand limit.

\section{Material and Methods}

The study was conducted in the Conservative Dentistry and Endodontics unit, Department of Dentistry, Faculty of Medicine, Pharmacy and OdontologyStomatology of Cheikh Anta Diop University of Dakar. The experimental protocol was approved by the ethical committee of the Ministry of Health of Senegal. A total of 90 extracted human mandibular molars with intact crowns and curved roots were selected. All molars were collected from three dental offices in Dakar, capital of Senegal. Extractions were indicated for periodontal or orthodontic reasons. The teeth showed no apical resorption or previous treatment.

After debridement of root surfaces, they were cleaned with soap and disinfected with $2.5 \%$ sodium hypochlorite $(\mathrm{NaOCl})$ (Septodont, Saint-Maure-Des fossées, France). The teeth were then stored in a saline solution for 15 days. Front and side preoperative anteroposterior radiographs were taken and an endodontic access cavity was prepared on each tooth. After navigation of the MB canals, teeth with apical canal diameter compatible with a \#15 K-file (Dentsply Maillefer, Ballaigues, Switzerland), a radius of curvature ranging between 5.0 and $9.0 \mathrm{~mm}$ and an angle of 
curvature between $25^{\circ}$ and $35^{\circ}$ (according to Schneider's method), were included. ${ }^{11}$ Then a \#15 K-file was placed in the MB canal and pre-instrumentation radiographs were taken. Radiographic images were amplified on a scale of 13×. Measurements were performed using Adobe Photoshop CS3 (Adobe Systems Inc., San Jose, CA).

The angle of curvature was measured in both buccolingual and mesiodistal directions. A straight line (a) was plotted along the right coronal portion of the canal parallel to the long axis. The point where the canal deviates from this line to initiate the curvature was marked point A. A second line (b) was drawn to connect the apical foramen (point B) to point A. The angle of curvature was the acute angle formed by straight lines (a) and (b) and was measured using Photoshop software (Fig. 1A).
A

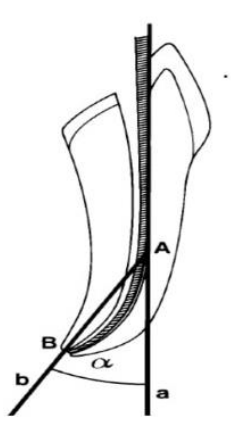

B

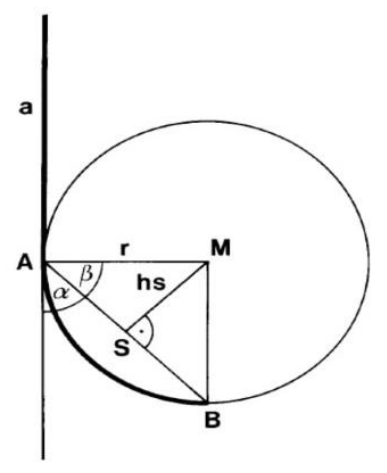

Fig. 1: (A): Measuring the angle of curvature ( $\alpha$ ) between lines a and $b$; (B): Calculation of the radius (r) of a curved canal. The root canal is shown as a bold line

The curve between point $A$ and point $B$ is a circular arc, which defines the curved portion of the canal (Fig. $1 \mathrm{~A}$ and $\mathrm{B}$ ). The radius of curvature can be calculated based on the measured length of the arc $(S)$ between the points $\mathrm{A}$ and $\mathrm{B}$. The arc $(\mathrm{S})$ was measured using a computer program. The radius of curvature was calculated based on the geometrical principles of an isosceles triangle. The formula is as follows: $\mathrm{R}=\mathrm{S} / 2 \sin \alpha$ where $\mathrm{S}$ is the arc between the points $\mathrm{A}$ and $\mathrm{B}$ and $\alpha$ is the angle of curvature.

The initial working length (WL) was obtained by subtracting $1 \mathrm{~mm}$ from the length obtained after the appearance of the tip of a K-file inserted in the canal. This length was verified using radiography with front and side images.

After evaluation of the initial WL, root canal shaping of teeth was carried out, with each tooth maintained in a tooth holder (Protrain, Simit Dental, Montova, Italy). Canal shaping was done with ProTaper ${ }^{\circledR}$ instruments (Dentsply Maillefer, Ballaigues, Switzerland) in a brushing motion starting from S1 file to reach the initial WL. Then S2, F1 and F2 were used in the WL according to the manufacturer's instructions. The canals were irrigated with $2.5 \% \mathrm{NaOCl}$ solution and dried using paper cones (DentsplyMaillefer, Ballaigues, Switzerland).

Based on the degree and the radius of curvature, teeth were allocated into three identical groups of 30 teeth each ( $\mathrm{L}, \mathrm{V}$, and $\mathrm{T})$. The homogeneity of the three groups with respect to the degree and the radius of curvature was assessed using Kruskal Wallis's test.

In Group L, after cleaning and shaping, a finger spreader (Micro-Mega, Besançon, France) with a diameter corresponding to the apical diameter of the prepared canal was chosen so that it reaches the WL. A master cone (DentsplyMaillefer, Ballaigues, Switzerland) was adjusted, sealed and finally compacted at the apical limit of obturation. Cones accessorieswere added and compacted, one by one as needed to hermetically seal the canal system. An X-Ray was used to visualize the obturation and to determine the cone section by the Machtou heat carrier (Dentsply-Maillfer, Ballaigues, Suisse) heated to red. The last step of the obturation was the vertical compacting using a large diameter of Machtou plugger (Dentsply Maillefer, Ballaigues, Switzerland).

Warm vertical compacting (group V) was carried out in two consecutive steps: a descending phase and an ascending phase. After the choice and trial of Machtou pluggers and master cone, the later one was sealed and compacted during the descending phase until the apical third. Then, during the ascending phase, a cone identical to the master cone was cut in fragments of 3 to $5 \mathrm{~mm}$ in length excluding its apical extremity. The fragments were softened, put in place and compacted. This procedure was repeated until the canal was completely filled using the Machtou pluggers of increasing diameters.

In Group $\mathrm{T}$, the prepared canal was explored by an instrument called "Verifier ${ }^{\circledR} »$ (with dimensions equivalent to the tutor not covered by gutta-percha). A control X-Ray ensured the good position of the Verifier ${ }^{\circledR}$ to confirm the right choice of the obturator. The chosen obturator was heated in an oven, the Thermaprep ${ }^{\circledR}$ (Dentsply Maillfer, Ballaigues, Sweden) then inserted into the canal (already dried and covered by a sealing cement) in an apical linear slow but firm motion. Once the WL is reached, the pressure was maintained to compensate for the retraction of the gutta-percha consecutive to the cooling of temperature.

After each canal obturation, a final X-Ray verified the quality of the obturation. The obturation limit was considered adequate if it is located $0-2 \mathrm{~mm}$ from the radiologic apex. Under-obturation was considered when the limit was beyond $2 \mathrm{~mm}$ from the radiologic apex. Over-obturation referred to a dense sealing with material overflow. Over-extension referred to obturation material overflow with lack of apical sealing. Density was assessed based on the presence of voids in the canal. The 
location of existing voids must be précised (coronal third, mid third, and apical third).

During all radiographic procedures, the teeth were placed in a tooth holder. The X-ray tube (Kodak, Paris, France) was oriented perpendicular to the axis of the roots. Radiographs of each root canal were taken from vestibular (clinical) view and mesial or distal (proximal) view. The exposure time was the same for all X-rays with a constant source-film distance of $50 \mathrm{~cm}$ and an object-film distance of $5 \mathrm{~mm}$. Radiographic images were recorded in a computer and numbered serially.

Data were analyzed using the Kruskal Wallis test. Differences were significant with a two-sided $\alpha<0.05$.

\section{Results}

Teeth characteristics are summarized in table 1. Canal obturation limit from all different techniques was overall adequate and was estimated overall to occur in $59 \%$ of cases. Specifically, most adequate obturations were achieved with the warm vertical condensation in $66.8 \%$ of cases. This technique also presented two cases of under-obturation (Table 1).

Thermafil ${ }^{\circledR}$ technique was associated with a higher proportion of over-obturation accounting for $46.7 \%$ of obturated canals. Cold lateral condensation was associated with a higher proportion of over-extension accounting for $33.3 \%$ of obturated canals. The difference between the three techniques of canal obturation was statistically significant with a p-value $=0.0001$ (Table 2 ).

The overall result regarding obturation density showed a void in 59\% of obturated canals. The majority of voids were located in the coronal third $(41 \%)$, followed by the mid third $(36 \%)$ and the apical third $(23 \%)$. Overall, warm vertical condensation was associated with the largest proportion of voids (90\% of cases). Comparatively, cold lateral condensation was associated with voids in $70 \%$ of cases and the lowest proportion of voids was found in the Thermafil ${ }^{\circledR}$ group $(16.7 \%$ of cases). Concerning the location of voids, cold lateral condensation caused more voids to the mid and apical thirds with respectively ( $26.7 \%$ and $23.3 \%$ of cases). The difference in density among the three canal obturation techniques was statistically significant with a $\mathrm{p}$-value $=$ 0.0001 (Table 3).

\section{Discussion}

In this laboratory study, we compared three canal obturation techniques: Thermafil $^{\circledR}$, warm vertical condensation and cold lateral condensation in mesiobuccal canals of 90 mandibular molars. The best outcomes were achieved with the technique of condensation by warm gutta.

The study of root canal shaping and filling in the laboratory was done using experimental models: the resin simulator ${ }^{12}$ or extracted teeth. ${ }^{13,11,14}$ The use of resin simulators standardizes the diameter, length, angle and the radius of canal curvature. Thus, variations in human teeth's canals can be eliminated by using resin simulators. However, human teeth were used in this study for a better representation of clinical conditions. Indeed, resin is different from human dentine in terms of surface texture and hardness. The Knoop hardness value for the resin blocks is 36 , whereas for dentine this value is between 40 and 72 according to Patterson..$^{15}$ In addition, the major drawback of simulators is the generation of heat caused by the friction of the rotating instruments, which can soften the resin that stickson the instruments' blade and causetheir deformation or breakage. Despite the morphological variations in human teeth, several studies on root canal shaping and filling between different techniques have been carried out on extracted teeth. ${ }^{16-19}$ The comparison of the three groups in this study showed good homogeneity between them. There were no statistically significant differences in the radius and angle of curvature between the three groups and a single technique of canal preparation $\left(\right.$ Protaper $^{\circledR}$ ) was used for all type of canal obturation. In fact, Protaper $^{\circledR}$ allows for an optimal conicity and subsequently a complete obturation of the endocanal system regardless of the used technique. ${ }^{20}$ Finally, in accordance with the manufacturer recommendations, it was suitable for curved canals used in our study.

The evaluation of the obturation in this study was done by X-Ray. The evaluation of the density and the limit was optimal using two X-Ray views: proximal and vestibulo-lingual. Furthermore, because of the complexity of the endodontic system, many laboratory studies have used this model regardless of the system used for canal shaping and obturation. ${ }^{21}$

In the current endodontic literature, two types of errors are commonly described in the canal preparation, limit and obturation: errors by incompletion (under obturation) and errors by excess (over-obturation and over-extension).

Under-obturationis defined by a distance between the apical limit of obturation and the radiologic apex beyond $2 \mathrm{~mm}$. Clinical studies show that treatment success of under obturated teeth with preoperative apical lesion drops from $94 \%$ to $68 \%$ when compared to teeth undergoing complete obturation. ${ }^{22}$ Chances for success also drop by $14 \%$ for each $\mathrm{mm}$ lost in the working length for the same teeth. Our findings indicate that warm vertical condensation leads to a higher proportion of under-obturation. This finding is certainly related to the major difficulty obturating the apical third of a curved canal during the descending phase of the technique. ${ }^{23}$ In fact, Matysiak and $a .^{24}$ considers under-obturation as one of the major inconvenient of canal obturation by warm vertical obturation. The lack of sealing of the apical part becomes a concern in presence of a necrotic pulp and/or an established periradicular lesion. For many authors, this inconvenience is significantly correlated with the presence of apical lesions. According to Sjörgren ${ }^{25}$ these under-obturations due to warm vertical condensation are responsible for $6 \%$ and $32 \%$ of failure based respectively on obturation limit and apical lesion. 
In the other hand, over-obturation refers to teeth in which the obturation is beyond the radiologic apex with a good apical sealing. Clinical studies show that overobturated teeth have a reduced healing prognosis. ${ }^{22,26}$ However, $76 \%$ of over-obturated teeth heal perfectly if the treatment is conducted in optimal conditions. ${ }^{22}$ This is however not a plea in favor of over-obturation because the cement used for root canal obturation and the guttapercha can be irritating for peri radicular tissue and maintain an inflammatory reaction. Gutta-percha can also act as a foreign body and cause an immune reaction by the presence of giant cells or serve as a matrice for the formation of a bacterial biofilm with germs that are more resistant to the immune defense, especially phagocytosis. However, treatment failure associated with overobturations often caused by a co-existing intra or extra radicular infection. ${ }^{26}$ Our findings indicate that Thermafil $^{\circledR}$ is associated with the highest proportion of over obturation. This is explained by the use of a plastic tutor causing a strong pressure to the apex associated with a lateral pressure at the introduction of the obturator into the canal. These two pressures result in a good density often with an over spread of the material in case of permeability of the apex. This inconvenient of Thermafil ${ }^{\circledR}$ system is mentioned by Cantatore ${ }^{27}$ in a study comparing it with the B system. However, many authors do not consider this inconvenience unfavorable to the success of endodontic treatment. ${ }^{26}$

Cold lateral condensation was associated with the highest proportion of overextension. This reflects a great number of important anomalies at the apex associated with over-spread of the obturation material. In fact, often, the use of lateral follower in curved canals does not allow for an adaptation of master cones into the apical third, therefore the cone is often pushed beyond the apical foramen due to the lack of sealing at this level. ${ }^{28}$ Together, these two disadvantages (lack of apical sealing and over-spread of the obturation material) explain why the overextension seriously compromises the chances of success of the endodontic treatment. ${ }^{26}$
In respect to canal obturation limit, Thermafil ${ }^{\circledR}$ is particularly adapted to curved canals ( $\mathrm{p}<0.05)$.

In addition to an optimal limit, the goal is to have a homogeneous and dense obturation without voids in the obturation or between the obturation and canal walls. ${ }^{29,30}$ In theory, inadequate density can lead to failure due to micro infiltration through the obturation. Obturation density can be an indicator of the capacity of the obturation to prevent canal infection. Therefore, obturation density and lateral sealing to canal walls are criterions that have been analyzed in many studies. ${ }^{26}$ Studies that used those criterions considered that the obturation must be dense and homogeneous without voids or spaces between the obturation and canal walls. Many studies found that the less dense and homogeneous the obturation, the worse the impact on the results. ${ }^{31,32}$ Eriksen and Bjertness found that the prevalence of apical parodontitis was higher in obturation with inadequate density, unlike other studies. ${ }^{33-36}$ Chueh and al. and Kirkvang and $a l$. showed that dense and homogeneous radicular obturations without voids are highly correlated with a low risk of post-operative pathologies. ${ }^{31,34}$

Our results show that the technique of cold lateral condensation gives less favorable outcomes in apical and mid thirds where we can locate lateral, secondary and accessory canals. These results are in accordance with results of Brothman indicating that a vertical compacting allows a filling up to twice the number of lateral canal compared to a simple lateral condensation. ${ }^{37}$ Seemingly, Clark and ElDeeb showed a higher filling rate of lateral canals with Thermafil ${ }^{\circledR}$ compared to simple lateral condensation and Dulac and $a l$. showed that Thermafil ${ }^{\circledR}$ allowed the filling of lateral canals at all levels compared to the technique of lateral condensation. ${ }^{38,39}$ Furthermore, the study of Goldberg and al. indicated that Thermafil ${ }^{\circledR}$ is the technique associated with the highest rate of canal filling compared to lateral condensation. ${ }^{40}$

Based on the results regarding obturation density, the techniques using warm guttapercha are more adapted to the tridimensional obturation of curved canals.

Table 1: Teeth characteristics

\begin{tabular}{|l|c|c|c|c|c|c|}
\hline \multirow{2}{*}{ Techniques } & \multicolumn{3}{|c|}{$\begin{array}{c}\text { Degree of curvature } \\
\text { (degrees) }\end{array}$} & \multicolumn{3}{c|}{ Radius of curvature (mm) } \\
\cline { 2 - 7 } & Mean (SD) & Min & Max & Mean(SD) & Min & Max \\
\hline $\begin{array}{l}\text { Cold lateral } \\
\text { condensation }\end{array}$ & $31.36(3.28)$ & 25 & 35 & $7.53(1.09)$ & 5.2 & 9 \\
\hline $\begin{array}{l}\text { Warm vertical } \\
\text { condensation }\end{array}$ & $31.38(3.29)$ & 25.1 & 35 & $7.54(1.1)$ & 5.1 & 9 \\
\hline Thermafil ${ }^{\circledR}$ & $31.36(3.27)$ & 25 & 35 & $7.6(1.2)$ & 5.2 & 9 \\
\hline P-value & \multicolumn{3}{|c|}{1.0} & \multicolumn{3}{c|}{1.0} \\
\hline
\end{tabular}

Table 2: Obturation limit by obturation techniques

\begin{tabular}{|c|c|c|c|c|c|c|c|c|}
\hline Obturation limit & \multicolumn{9}{|c|}{ Obturation Techniques } & \multicolumn{3}{c|}{ Total } \\
\cline { 2 - 10 } & \multicolumn{2}{|c|}{ T } & \multicolumn{2}{|c|}{ V } & \multicolumn{2}{c|}{ L } & \multicolumn{2}{c|}{} \\
\cline { 2 - 10 } & $\mathbf{n}$ & $\boldsymbol{\%}$ & $\mathbf{n}$ & $\boldsymbol{\%}$ & $\mathbf{n}$ & $\mathbf{\%}$ & $\mathbf{n}$ & \% \\
\hline Adequate obturation & 14 & 46.7 & 20 & 66.8 & 19 & 63.4 & 53 & 59 \\
\hline
\end{tabular}




\begin{tabular}{|l|c|c|c|c|c|c|c|c|}
\hline Over-obturation & 14 & 46.7 & 0 & 0 & 1 & 3.3 & 15 & 17 \\
\hline Over-extension & 2 & 6.6 & 8 & 26.6 & 10 & 33.3 & 20 & 22 \\
\hline Under-obturation & 0 & 0 & 2 & 6.6 & 0 & 0 & 2 & 2 \\
\hline Total & 30 & 100 & 30 & 100 & 30 & 100 & 90 & 100.0 \\
\hline P & \multicolumn{7}{|c|}{0.0001} \\
\hline
\end{tabular}

Table 3: Density of obturation by obturation techniques (number and percentage)

\begin{tabular}{|l|c|c|c|c|c|c|c|c|}
\hline \multirow{2}{*}{ Voids } & \multicolumn{2}{|c|}{ T } & \multicolumn{2}{c|}{ V } & \multicolumn{3}{c|}{ L } & \multicolumn{2}{c|}{ Total } \\
\cline { 2 - 10 } & $\mathbf{n}$ & $\mathbf{\%}$ & $\mathbf{n}$ & $\mathbf{\%}$ & $\mathbf{n}$ & $\mathbf{\%}$ & $\mathbf{n}$ & $\mathbf{\%}$ \\
\hline Absence of voids & 25 & 83.3 & 3 & 10 & 9 & 30 & 37 & 41.1 \\
\hline Voidsat coronal third & 1 & 3.3 & 15 & 50 & 6 & 20 & 22 & 24.5 \\
\hline Voidsat mid third & 4 & 13.4 & 7 & 23.4 & 8 & 26.7 & 19 & 21.1 \\
\hline Voidsat apical third & 0 & 0 & 5 & 16.6 & 7 & 23.3 & 12 & 13.3 \\
\hline Total & 30 & 100 & 30 & 100 & 30 & 100 & 90 & 100 \\
\hline P & \multicolumn{9}{|c|}{0.0001} \\
\hline
\end{tabular}

\section{Conclusion}

Our study indicates that techniques of Thermafil ${ }^{\circledR}$ and warm vertical condensation which compact warm gutta-percha give the best results for the obturation of curved canals in respect with limit and density when compared to cold lateral condensation.

However, it is important to note that other factors like a rigorous preparation, a proper sterilization and a waterproof coronal restoration contribute to the success of endodontic treatment.

Funding: No funding sources.

Conflict of interest: None declared.

\section{References}

1. Naseri M, Kangarlou A, Khavid A, Goodini M. Evaluation of the quality of four root canal obturation techniques using micro-computed tomography. Iran Endod J 2013;8(3):8993.

2. Eskandarloo A, Karkehabadi H, HoseiniHashemi SZ, Ahmadi M, Hendi SS. Radiographic quality of root canal obturation performed by fifth year students of hamadan dental school. Iran Endod J 2017;12(2):236-41.

3. Claisse A. Obturation canalaire: technique combinée, Système B, Thermafil, Microseal (B32). Chir Dent Fr 1999;960:18-20.

4. Simon S. Le traitement endodontique : l'essentiel. Clinic 2010;31:1-5.

5. Schäfer E, Köster M, Bürklein S. Percentage of guttapercha-filled areas in canals instrumented with nickeltitanium systems and obturated with matching single cones. J Endod 2013;39:924-8.

6. Hale R, Gatti R, Glickman GN, Opperman LA. Comparative analysis of carrier-based obturation and lateral compaction: A retrospective clinical outcomes study. Int $J$ Dent 2012;2012:954675.

7. Schilder H. Obturation des canaux radiculaires en trois dimensions. J Dent Québec 1980;17:33-40.

8. Yilmaz A, Karagoz-Kucukay I. In vitro comparison of gutta-percha-filled area percentages in root canals instrumented and obturated with different techniques. $J$ Istanb Univ Fac Dent 2017;51(2):37-42.

9. Marques-Ferreira M, Abrantes M, Ferreira HD, Caramelo F, Botelho MF, Carrilho EV. Sealing efficacy of system B versus Thermafil and Guttacoreobturation techniques evidenced by scintigraphicanalysis. J Clin Exp Dent 2017;9(1):56-60.

10. Jindal D, Sharma M, Raisingani D, Swarnkar A, Pant M, MathurR.Volumetric analysis of root filling with cold lateral compaction, Obtura II, Thermafil, and Calamus using spiral computerized tomography: An In vitro Study. Indian J Dent Res 2017;28(2):175-80.

11. Burklein S, Hintschitza K, Dammaschke T, Schafer E. Shaping ability and cleaning effectiveness of two singlefile systems in severely curved root canals of extracted teeth Reciproc and Wave One versus two and ProTaper. Int Endod J 2012;45:449-61.

12. Berutti E, Paolino DS, Chiandussi G, Alovisi M, Cantatore G, Castellucci A. Root canal anatomy preservation of Wave One reciprocating files with or without glide path. $J$ Endod 2012;38(1):101-4.

13. Talati A, Moradi S, Forghani M, Monajemzadeh A. Shaping ability of nickel-titanium rotary instruments in curved root canals. Iran Endod J 2013;8(2):55-8.

14. Berutti E, Chiandussi G, Paolino DS, Scotti N, Cantatore G, Castellucci A. Effect of canal length and curvature on working length alteration with Wave One reciprocating files. J Endod 2011;37(12):1687-90.

15. Pecqueur $P$. Instrumentation unique : une nouvelle ère endodontique. Thèse Chir Dent Toulouse 2012;2012(TOU3):3065.

16. Yared G. Canal preparation using only one Ni-Ti rotary instrument: preliminary observations. Int Endod $J$ 2008;41(4):339-44.

17. Burklein S, Hiller C, Huda M, Schafer E. Shaping ability and cleaning effectiveness of two versus coated and uncoated Easyshape instruments in severely curved root canals of extracted teeth. Int Endod J 2011;44:447-57.

18. Stern S, Patel S, Foschi F, Sherriff M, Mannocci F. Changes in centring and shaping ability using three nickeltitanium instrumentation techniques analysed by microcomputed tomography (muCT). Int Endod $J$ 2012;45(6):514-23.

19. Paque F, Zehnder M, De-Deus G.Microtomography-based comparison of reciprocating single-file F2 ProTaper technique versus rotary full sequence. $J$ Endod 2011;37:1394-7.

20. Pentelechu C, Colceriu L, Pastrav O, Culic C, Chinoui.In vitro evaluation of root canal preparation with two rotary instrument systems -Pro Taper and Hero Shaper.Clujul Med 2015;88(3):395-402.

21. Bane K, Faye B, Sarr M, Niang So, Ndiaye D, Machtou P. Root canal shaping by single-file systems and rotary 
instruments: A laboratory study. Iran Endod $J$ 2015;10(2):135-39.

22. Dupont AM. L'obturation canalaire définitive : quelles techniques pour une utilisation quotidienne? Cah Assoc Dent France 1998;2(2):26-34.

23. Hua Xi Kou Qiang Yi XueZaZhi. Difficulties and misunderstandings of root canal filling. XinZu 2017:1;35(3):232-8.

24. Matysiak M, Tardieu-Fabre F, Galliot M. Détermination des critères radiologiques qualitatifs contribuant significativement au résultat radiologique d'un traitement endodontique. Rev Med Ass Maladie 2003;34:111-20.

25. Sjögren U, Figdor D, Persson S, Sundqvist G. Influence of infection at the time of root filling on the outcome of endodontic treatment of teeth with apical periodontitis. Int Endod J 1997;30(5):297-306. Erratum in: Int Endod J 1998;31(2):148.

26. Viteaux A, Guigand M. Echecs : sommes-nous toujours responsable? Inf Dent 2010;92(22):89-96.

27. Cantatore G. Thermafil versus System B. Endod Prac 2001;4(5):30-39.

28. Metzger Z, Zary R, Cohen R, Teperovich E, Paque F. The quality of root canal preparation and root canal obturation in canals treated with rotary versus Selfadjusting Files: A three-dimensional micro- computed tomographic study. $J$ Endod 2010;36:1569-73.

29. Pommel L, PertotWJ.Obturation de l'endodonte. In : Simon S, Machtou P, Pertot WJ, éditeurs. Endodontie. Paris: Editions CdP,2012:243-81.

30. Saeed Moradi, Maryam Gharechahi. Quality of Root Canal Obturation Performed by Senior Undergraduate Dental Students. Iran Endod J 2014;9(1):66-70.

31. Chueh LH, Chen SC, Lee CM, Hsu YY, Pai SF, Kuo ML, Chen CS, Duh BR, Yang SF, Tung YL, Hsiao CK. Technical quality of root canal treatment in Taiwan. Int Endod J 2003;36(6):416-22.

32. Stoll R, Betke K, Stachniss V. The influence of different factors on the survival of root canal fillings: a 10-year retrospective study.J Endod 2005;31(11):783-90.
33. Eriksen HM, Bjertness E. Prevalence of apical periodontitis and results of endodontic treatment in middle-aged adults in Norway. Endod Dent Traumatol 1991;7(1):1-4.

34. Kirkevang LL, Horsted-Bindslev P, Orstavik D, Wenzel A. A comparison of the quality of root canal treatment in two Danish subpopulations examined 1974-75 and 1997-98. Int Endod J 2001;34(8):607-12.

35. Dugas NN, Lawrence HP, Teplitsky PE, Pharoah MJ, Friedman S. Periapical health and treatment quality assessment of root-filled teeth in two Canadian populations. Int Endod J 2003;36(3):181-92.

36. Boucher Y, Matossian L, Rilliard F, Machtou P. Radiographic evaluation of the prevalence and technical quality of root canal treatment in a French subpopulation. Int Endod J 2002;35(3):229-38.

37. Brothman P. A comparative study of the vertical and the lateral condensation of gutta-percha. J Endod 1981;7(1):2730.

38. Clark DS, ElDeeb ME Apical sealing ability of metal versus plastic carrier Thermafillobturators. $J$ Endod 1993;19:4-9.

39. Dulac KA, Nielsen CJ, Tomazic TJ, Ferrillo PJ, Hatton JF. Comparison of the obturationof lateral canals by six techniques. J Endod 1999;25:376-80.

40. Goldberg F, Artaza L P, De Silvio A. Effectiveness of different obturation techniques in the filling of simulated lateral canals. J Endod 2001;27:362-4.

How to cite the article: Bane K., Niang S., Léye-Benoist F., Kouakou K., Touré B. Evaluation of the quality of three canal obturation techniques: A laboratory study. IP Indian J Conserv Endod 2018;3(3):86-91. 